\title{
The approach to dysplasia surveillance in inflammatory bowel disease
}

\author{
Remo Panaccione MD
}

$\mathrm{T}$ he association between inflammatory bowel disease (IBD) and the development of colorectal cancer (CRC) was first described over eight decades ago (1). However, it was not until the late 1970s that the true clinical significance of this association was appreciated. It is now accepted that both ulcerative colitis (UC) and Crohn's disease (CD) are associated with an increased risk of CRC (2). It is believed that CRC arises from dysplastic precursor lesions. Unlike the typical dysplasia-carcinoma sequence, the dysplastic lesions are believed to arise in flat mucosa and do not assume a mass-like or polypoid lesion. A recent meta-analysis (3) of 116 published articles estimated the risk of CRC in UC to be $2 \%$ at 10 years, $8 \%$ at 20 years and $13 \%$ at 30 years. Aside from the duration of the disease, the extent (4), family history $(5,6)$ and early onset of CRC $(7)$, along with concomitant primary sclerosing cholangitis (PSC) $(8,9)$, are risk factors for the development of CRC. Similar rates of CRC have recently been demonstrated in patients with CD (10). This epidemiological relationship has led to the practice of surveillance colonoscopy in groups at risk. The initial intent of entering patients into a dysplasia surveillance program was to stratify patients into highrisk groups in need of proctocolectomy and low-risk groups who could continue in the surveillance program.

\section{SPEAKING THE SAME LANGUAGE}

It is paramount when discussing this topic to ensure that definitions are clearly specified. Dysplasia by definition is neoplasia confined to the epithelium. When undertaking surveillance colonoscopy in patients with IBD, dysplasia can take many forms. If the mass is polypoid, similar to that found in the colon of a non-IBD patient, it is termed an adenoma-like mass. On the other hand, if the mass is flat with irregular borders then it is termed a dysplasia-associated lesion or mass. Finally, if dysplasia is found on a random biopsy in endoscopically 'normal' mucosa, it is termed flat dysplasia.

\section{THE SURVEILLANCE PARADIGM}

Surveillance is generally started eight years after diagnosis for extensive colitis (UC and CD) and 10 to 12 years after diagnosis for left-sided UC. Adequate biopsies are taken and patients return at one to three year intervals for repeat surveillance for the remainder of their lifetime or until dysplasia or CRC is detected and proctocolectomy recommended (11). Despite this intensive regimen, surveillance colonoscopy has never been shown to decrease CRC-related mortality in UC $(12,13)$.

\section{THE SUCCESSFUL SURVEILLANCE PARADIGM}

For the surveillance paradigm to be beneficial to patients, certain assumptions need to be made. These assumptions are that:

- those performing surveillance colonoscopy for dysplasia are performing adequate number of biopsies to detect the lowest grade of dysplasia which is associated with a finding of CRC (14);

- pathologists can accurately detect dysplasia in tissue specimens;

- the interpretation of biopsy specimens can be confirmed by a second independent pathologist; and

- the endoscopist appreciates the significance of the interpretation of the tissue histology (low-grade dysplasia [LGD], high-grade dysplasia [HGD] and carcinoma) and makes the appropriate recommendation to the patient.

Unfortunately, many of these assumptions are never met and can lead to inappropriate recommendations. It has been demonstrated that 33 jumbo forcep biopsies are needed to detect the highest degree of dysplasia or CRC with $90 \%$ confidence (14). The number increases to 56 biopsies for the confidence level to increase to $95 \%$. A survey in the United Kingdom (15) reported that $57 \%$ of gastroenterologists take 10 or fewer biopsies during surveillance examinations. A preliminary report examining a single academic medical centre found that 20 or more biopsy specimens were available for histopathological review in only $18 \%$ of surveillance examinations (16). Even when adequate biopsies were taken, the interobserver agreement among pathologists was suboptimal (17). In a set of standard biopsies, there was complete

Inflammatory Bowel Disease Clinic, University of Calgary, Calgary, Alberta

Correspondence: Dr Remo Panaccione, Room 127, 3330 Hospital Drive North West, Calgary, Alberta T2N 4N1.

Telephone 403-210-9837, fax 403-270-7287, e-mail rpanacci@ucalgary.ca 
agreement on only four of 51 specimens (30\% missed LGD, 15\% missed HGD). The concordance was lowest for LGD and 30\% of normal specimens were classified as having LGD. In a survey of gastroenterologists and senior trainees only, 19\% could accurately define dysplasia, 69\% recommended colectomy for HGD and only 7\% recommended colectomy for LGD (18). In another study in the United Kingdom (17), of 341 gastroenterologists, only $4 \%$ recommended colectomy for LGD.

\section{THE APPROACH TO DYSPLASIA SURVEILLANCE}

Once the clinician has discussed with the patient the benefits and limitations of surveillance in IBD, the next step is to ensure that the practice of surveillance adheres to accepted methods. This essentially refers to obtaining an adequate number of biopsies from selected locations in the colon. As discussed previously, 33 random biopsies are required to detect the highest grade of dysplasia with $90 \%$ confidence. Obtaining fewer biopsies theoretically leads to missing areas of dysplasia when present and putting the patient at risk of progressing to CRC.

My approach is to begin surveillance at eight years after diagnosis in patients with ulcerative pancolitis and CD, and 10 to 12 years in left-sided UC or proctosigmoiditis. Followup surveillance colonoscopies are performed at one year and every other year respectively. In patients with an associated diagnosis of PSC, surveillance should begin at the time of diagnosis of the PSC and repeat surveillance colonoscopy continued on an annual basis.

Ideally, two nursing assistants are present in the endoscopy suite when patients are undergoing surveillance biopsies. This improves the efficiency of obtaining biopsies and saves valuable time. Unfortunately, this is not always possible. I record the length at which the cecal tip is reached. The endoscopy nurse then prepares four bottles (right colon, transverse colon, left colon and rectum). The practice of obtaining biopsies every $10 \mathrm{~cm}$ and placing them in separate containers makes little sense since it would be hard to find the same location on a subsequent colonoscopy. I then obtain four quadrant biopsies with jumbo forceps every $10 \mathrm{~cm}$ in the right colon and transverse colon. Because the majority of dysplastic lesions are found in the left colon, I double up on obtaining biopsies in this segment (obtaining biopsies every $5 \mathrm{~cm}$ ). Eight separate biopsies are taken in the rectum. Any suspicious areas (raised lesions, thickened folds, strictures or narrowing) should be biopsied separately and ideally 'tattooed' with India ink. In older patients who have polyps which

\section{REFERENCES}

1. Crohn B, Rosenberg H. The sigmoidoscopic picture of chronic ulcerative colitis (non-specific). Am J Med Sci 1925;170:220-8.

2. Itzkowitz SH, Harpaz N. Diagnosis and management of dysplasia in patients with inflammatory bowel diseases. Gastroenterology 2004;126:1634-48.

3. Eaden JA, Abrams KR, Mayberry JF. The risk of colorectal cancer in ulcerative colitis: A meta-analysis. Gut 2001;48:526-35.

4. Lashner BA, Silverstein MD, Hanauer SB. Hazard rates for dysplasia and cancer in ulcerative colitis: Results from a surveillance program. Dig Dis Sci 1989;34:1536-41.

5. Eaden J, Abrams K, Ekbom A, Jackson E, Mayberry J. Colorectal cancer prevention in ulcerative colitis: A case-control study. Aliment Pharmacol Ther 2000;14:145-53. represent sporadic adenomas, polypectomy is performed, followed by four quadrant biopsies around the polypectomy site, followed by 'tattooing' of the site.

\section{FINDING LGD - WHAT TO DO?}

Three recent publications have addressed this issue, unfortunately with conflicting results. Ullman et al (19) followed the outcomes of 46 patients with flat LGD diagnosed at Mount Sinai Hospital in New York after 1994. They found that:

- $23.5 \%$ of patients who underwent colectomy for flat LGD harboured more advanced pathology;

- the actuarial rate of progression to advanced neoplasia (HGD or CRC) was $53 \%$;

- advanced stage cancers occurred in three of the 46 patients, two of whom had dysplasia-free examinations within 12 months of their cancer diagnosis and none of whom had HGD before developing cancer; and

- no clinical variables, including the number of biopsies positive for LGD, were predictive of progression. Two other series, however, failed to show such a worrisome prognosis for LGD.

Befrits et al (20) followed 60 patients with flat LGD from a single centre in Sweden and found that none of them developed cancer on follow-up. In the series by Lim et al (21) from the United Kingdom, no meaningful progression to cancer was detected, but it is worth noting that patients whose dysplasia was diagnosed before 1983 were included. Unfortunately, these recent publications have failed to achieve consensus on the proper management of flat LGD in ulcerative colitis. If the data from Connell et al (22), Bernstein et al (23) and Ullman et al (19) are to be believed, surgery is the best option. If, however, a patient is willing to take some risk, then a nonsurgical approach should be entertained.

\section{THE FUTURE OF DYSPLASIA SURVEILLANCE}

One of the considerations as technology advances is that the accepted paradigm may change. It may be that with the present technology we cannot appreciate subtle mucosal changes and therefore in the setting of dysplasia in flat mucosa, proctocolectomy is often recommended. With advanced endoscopic techniques such as special staining, magnifying colonoscopies and high-definition signals, we may be able to better characterize flat dysplasia and employ endoscopic resection or ablation and avoid surgery.

6. Nuako KW, Ahlquist DA, Mahoney DW, Schaid DJ, Siems DM, Lindor NM. Familial predisposition for colorectal cancer in chronic ulcerative colitis: A case-control study. Gastroenterology 1998;115:1079-83.

7. Ekbom A, Helmick C, Zack M, Adami HO. Ulcerative colitis and colorectal cancer: A population-based study. N Engl J Med 1990;323:1228-33.

8. Broome U, Lindberg G, Lofberg R. Primary sclerosing cholangitis in ulcerative colitis: A risk factor for the development of dysplasia and DNA aneuploidy? Gastroenterology 1992;102:1877-80.

9. Brentnall TA, Haggitt RC, Rabinovitch PS, et al. Risk and natural history of colonic neoplasia in patients with primary sclerosing cholangitis and ulcerative colitis. Gastroenterology 1996;110:331-8. 
10. Friedman S, Rubin PH, Bodian C, et al. Screening and surveillance colonoscopy in chronic Crohn's colitis. Gastroenterology 2001;120:820-6

11. Itzkowitz SH, Present DH; Crohn's and Colitis Foundation of America Colon Cancer in IBD Study Group. Consensus conference: Colorectal cancer screening and surveillance in inflammatory bowel disease. Inflamm Bowel Dis 2005;11:314-21.

12. Choi PM, Nugent FW, Schoetz DJ Jr, Silverman ML, Haggitt RC. Colonoscopic surveillance reduces mortality from colorectal cancer in ulcerative colitis. Gastroenterology 1993;105:418-24.

13. Karlen P, Kornfeld D, Brostrom O, Lofberg R, Persson PG, Ekbom A. Is colonoscopic surveillance reducing colorectal cancer mortality in ulcerative colitis? A population based case control study. Gut 1998;42:711-4.

14. Rubin CE, Haggitt RC, Burmer GC, et al. DNA aneuploidy in colonic biopsies predicts future development of dysplasia in ulcerative colitis. Gastroenterology 1992;103:1611-20.

15. Eaden JA, Ward BA, Mayberry JF. How gastroenterologists screen for colonic cancer in ulcerative colitis: An analysis of performance. Gastrointest Endosc 2000;51:123-8.

16. Ullman TA, Croog V, Harpaz N, et al. Biopsy specimen numbers in the routine practice of surveillance colonoscopy in ulcerative colitis (UC). Gastroenterology 2004;126:A-471. (Abst)
17. Eaden J, Abrams K, McKay H, Denley H, Mayberry J. Inter-observer variation between general and specialist gastrointestinal pathologists when grading dysplasia in ulcerative colitis. J Pathol 2001;194:152-7.

18. Bernstein CN, Weinstein WM, Levine DS, Shanahan F. Physicians' perceptions of dysplasia and approaches to surveillance colonoscopy in ulcerative colitis. Am J Gastroenterol 1995;90:2106-14.

19. Ullman T, Croog V, Harpaz N, Sachar D, Itzkowitz S. Progression of flat low-grade dysplasia to advanced neoplasia in patients with ulcerative colitis. Gastroenterology 2003;125:1311-9.

20. Befrits R, Ljung T, Jaramillo E, Rubio C. Low-grade dysplasia in extensive, long-standing inflammatory bowel disease: A follow-up study. Dis Colon Rectum 2002;45:615-20.

21. Lim CH, Axon AT. Low-grade dysplasia: Nonsurgical treatment. Inflamm Bowel Dis 2003;9:270-2; discussion 273-5.

22. Connell WR, Lennard-Jones JE, Williams CB, Talbot IC, Price $\mathrm{AB}$, Wilkinson $\mathrm{KH}$. Factors affecting the outcome of endoscopic surveillance for cancer in ulcerative colitis. Gastroenterology 1994;107:934-44.

23. Bernstein CN, Shanahan F, Weinstein WM. Are we telling patients the truth about surveillance colonoscopy in ulcerative colitis? Lancet 1994;343:71-4. 


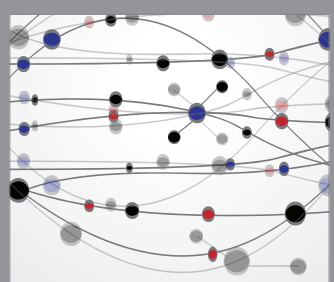

The Scientific World Journal
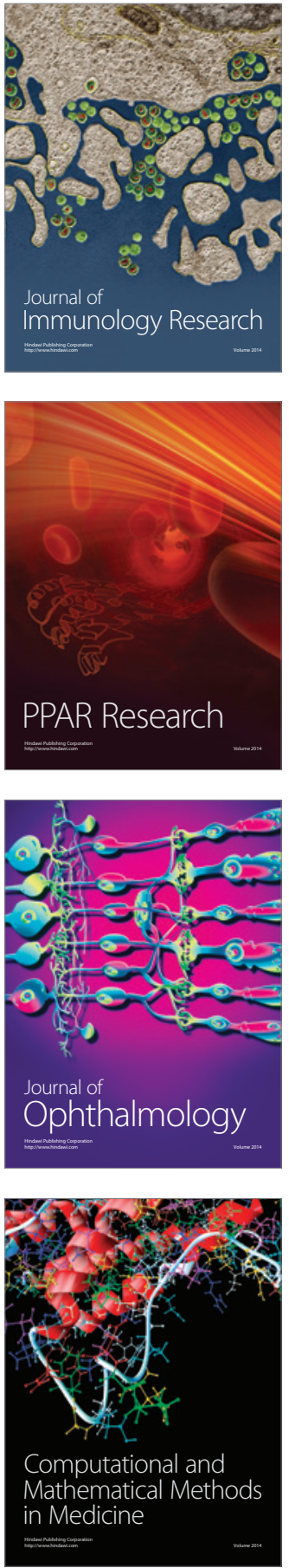

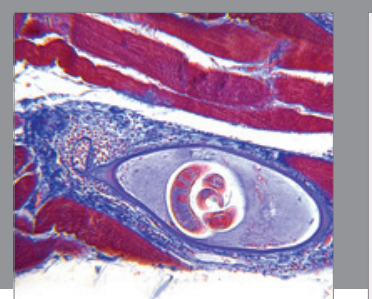

Gastroenterology Research and Practice

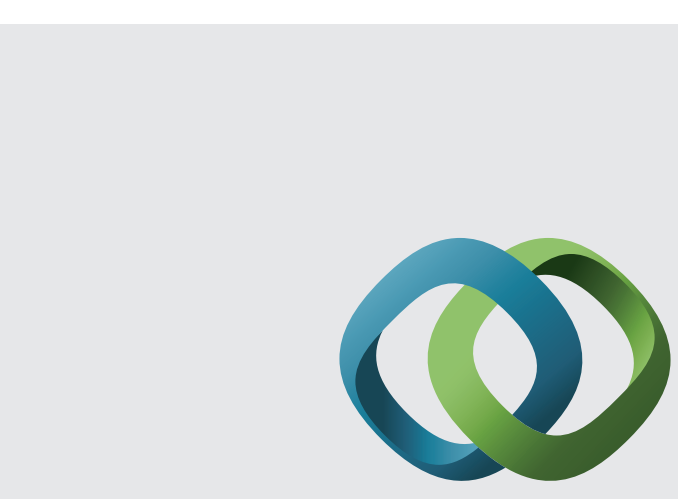

\section{Hindawi}

Submit your manuscripts at

http://www.hindawi.com
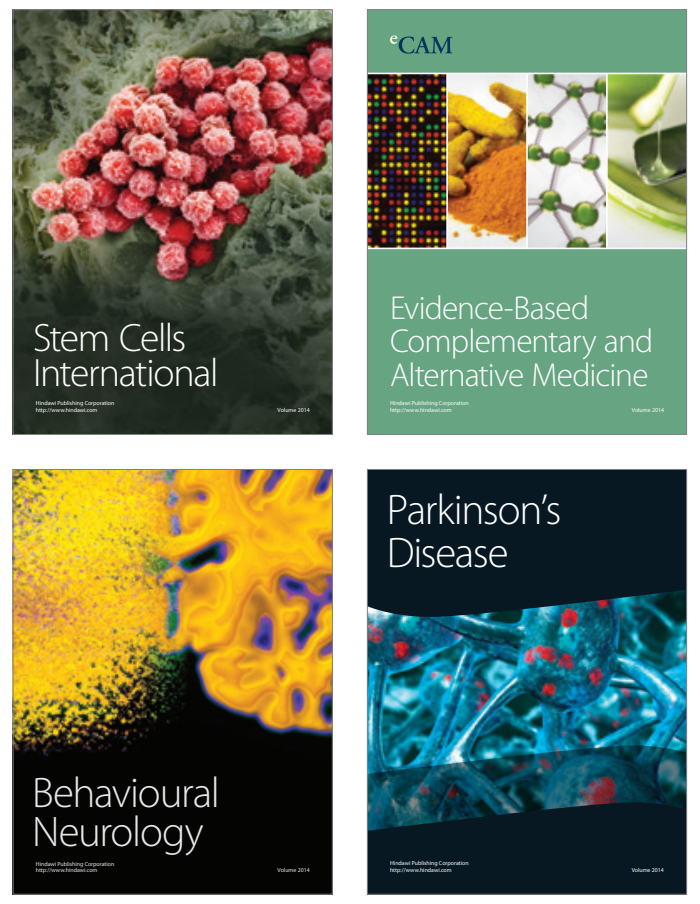
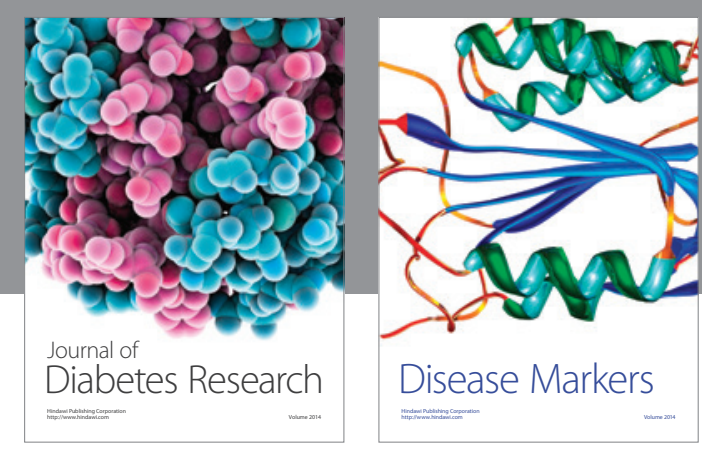

Disease Markers
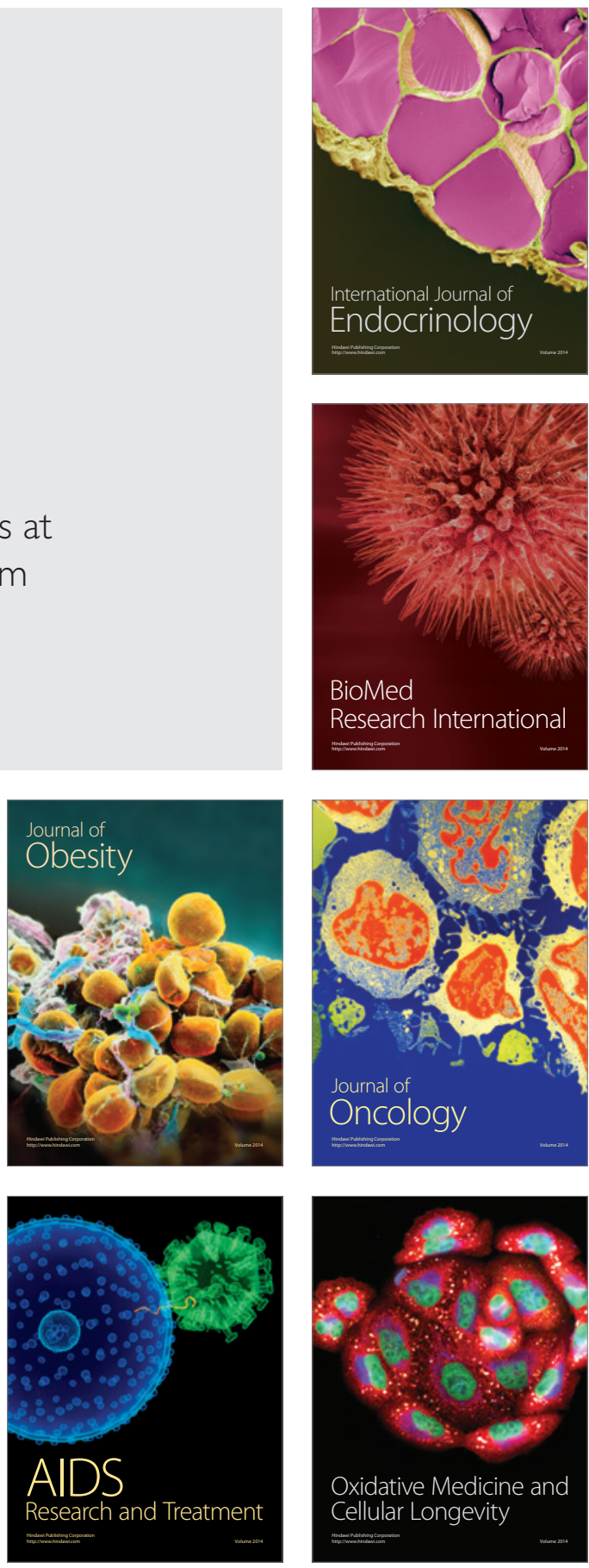